\title{
The Study of Interaction Features Used by Intermediate Iranian EFL Learners in Their Lexical Language Related Episodes
}

\author{
Ehsan Alijanian \\ English Department, Faculty of Foreign Languages, University of Isfahan, Iran \\ Saeed Ketabi \\ English Department, Faculty of Foreign Languages, University of Isfahan, Iran \\ Ahmad Moinzadeh \\ English Department, Faculty of Foreign Languages, University of Isfahan, Iran
}

\begin{abstract}
Negotiation of meaning refers to interactional work done by interlocutors to attain joint understanding when a communication difficulty comes about. This study uses a qualitative perspective to consider the development of participant utterances in interaction in every moment. 10 English as a foreign language learners in a language school in Iran were chosen to participate in a dictogloss activity in which they were required to describe a certain word. The interaction features in their lexical language related episodes were analyzed. The results indicate that students use a wide range of interaction features in their collaborations. These features help learners generate a scaffolding structure in the LLREs in which meaning discovering is made. The use of interactive features fostered metalinguistic awareness and encouraged learners' self-regulation.
\end{abstract}

Index Terms - interactions features, lexical language related episodes, Dictogloss, collaboration

\section{INTRODUCTION}

The investigation of language acquisition from an SCT viewpoint is founded on the work of Lev Vygotsky, who saw learning as a socially arranged and educated action. Vygotsky (1978) suggested the genetic law of social improvement to represent intellectual and etymological advancement. The genetic law of improvement stipulates that mental capacities, for example, memory and consideration are followed by an outside stage that unravels in the social domain. From this point of view, speech is characteristically joined with intuition such that higher mental capacities are mediated by social and typical devices.

More recently, work on the role of interaction in SLA has shifted away from pairs of learners transacting an information gap task towards the recasting (e.g., Lyster 1998; Long et al., 1998; Braidi, 2002) and focus-on-form episodes that are available in whole class settings (e.g., Ellis et al., 2001) and are often, although not always, initiated by a native speaker or teacher who has not encountered a communication failure, impasse, or breakdown, (i.e. who has understood what the non-native speaker meant) but who has chosen where some language focus would be most useful. Such a shift moves us away from classroom group work (in which learners interact with each other) towards a situation where a more competent speaker (the teacher, or a native speaker) chooses to turn the learner's attention productively from meaning and towards form (Foster\&Ohta, 2005). Much valuable work has been done on the way such feedback, recasting, and other language-related-episodes (Swain, 2001) might shift a learner's attention to language form. In this research, however, we wish to return the focus to interaction between non-native speakers working together on a classroom task because this is an extremely common and widely-promoted practice in communicative language teaching, and because the idea is still prevalent that, as SLA is facilitated through learners negotiating solutions to communication failures, such failures could be usefully engineered through classroom task design (Foster\&Ohta, 2005). In this view, there is an assumption that learners are on the whole not predisposed to focus on language form, but will do so when communication failure means they have to (Foster\&Ohta, 2005).

The Japanese language learners in Ohta's (2001) study provided and received assistance in a variety of ways. For example, they directly asked for, and received, assistance from each other, they continued utterances that a partner was having difficulty with, chimed in with suggestions, and offered and accepted corrections (Foster\&Ohta, 2005). Assistance was also provided less explicitly, for example, when a peer waited, providing a partner time to compose an utterance. Learner assistance to one another often resulted in assisted performance (Tharp \& Gallimore, 1991; Ohta, 2001); the creation of utterances that incorporated the assistance of another. Assistance given and utilized creates a 
discourse that is a joint performance, something which can be seen as an important precursor of individual production (Foster\&Ohta, 2005).

From a sociocultural perspective, the zone of proximal development (ZPD) is used to understand how assistance is related to language development. ZPDs are evident wherever one learner is enabled to do something by the assistance of another that he or she would not have been able to do otherwise (Foster\&Ohta, 2005). Vygotsky (1978) defines the ZPD as 'the distance between the actual developmental level as determined by independent problem solving and the level of potential development as determined through problem solving under adult guidance or in collaboration with more capable peers' (Vygotsky, 1978, p. 86). Ohta (2001) reformulated the ZPD for L2 learning as 'the distance between the actual developmental level as determined by individual linguistic production, and the level of potential development as determined through language produced collaboratively with a teacher or peer' (Ohta, 2001, p. 9) The implications of the ZPD for SLA are that what the learner can be assisted in doing is soon to be something that the learner will be able to do without help (Foster\&Ohta, 2005). From a cognitive perspective, we might say that what is within the zone of proximal development is within the learner's reach, but not yet fully incorporated into the learner's linguistic system. Language development might occur as this gap between individual and joint performance is filled and learners develop increased independence (Foster\&Ohta, 2005). Rather than occurring through a process of comprehending i+1 input, from this perspective language acquisition occurs as the learner is enabled to do things with language-in production as well as reception - that he or she could not have done without a nudge of assistance (Ohta, 2001).

Based on the above, the following research question will be addressed in this study: What are the languaging characteristics (interaction features) used by intermediate Iranian EFL learners in their lexical language related episodes?

\section{Methodology}

This study uses a qualitative perspective in its design. This qualitative approach makes it possible to consider the development of participant utterances in interaction in every moment. (Firth, 2009; Mori \& Markee, 2009). The detailed investigation of the interaction seems crucial for the interpretation of the results of the specific context of this study; such improvement can be "traced visibly in the course of talk between expert and novice" in the history of learning experiences" (Mitchells \& Myles, 2004, p. 198). Qualitative analysis is appropriate for the research questions because it lets the researcher obtain comprehensive information about the language development perceived in individuals or small groups (Aljaafreh \& Lantolf, 1994).

Participants in this study are intermediate English as a foreign language learners in a language school in Iran. In qualitative research purposeful sampling is recognized as the most common technique for selection of participants (Ellis \& Barkhuizen, 2005). Participants ranged in age from 23 to 32 and had at least three years of experience in studying English. The dictogloss was used as the instrument of data collection. During this dictogloss activity, learners are required to play a game. Learners should describe a certain word or concept written on the card during the reconstruction of story but they must not mention the forbidden words (three to five) written on their card in their explanation. This challenging task as a plan that is contributing to much collaborative talk is what is needed in this study in investigating the lexical language related episodes. In every dictogloss task, each group had to discuss four vocabulary items while they were involved in the reconstruction of the story and they also had to use these words in their reconstruction.

\section{Data Analysis}

The sociocultural methodology is concerned not only with learner language but also with linguistic context (Ellis \& Barkhuizen, 2005); for the sociocultural researcher, "language learning takes place in interaction, and not simply as a result of interaction" (p. 236). Consequently, this research was concerned with analyzing lexical related interactions as it occurred using the qualitative approach.

In order to identify languaging characteristics to examine the nature of languaging, LLREs will be analyzed in terms of the interaction features.

TABLE 1.

INTERACTIVE FEATURES OF LLRES (ADAPTED FROM ELLIS, 1999)

\begin{tabular}{|l|l|}
\hline LLRE Interactive features & Description \\
\hline $\begin{array}{l}\text { Clarification requests } \\
\text { Confirmation check }\end{array}$ & $\begin{array}{l}\text { Participant asks for explanation of a previous utterance. } \\
\text { Participant check their own comprehension of what their } \\
\text { conversation partner said. }\end{array}$ \\
\hline Repetitions & $\begin{array}{l}\text { Participants assume that their partner did not } \\
\text { comprehend, so they check if he did or not. }\end{array}$ \\
\hline Requests for repetitions & $\begin{array}{l}\text { Participant repeats another student's utterance as a type } \\
\text { of confirmation check. }\end{array}$ \\
\hline Scaffolding & Participants ask that their partner repeat an earlier utterance. \\
\hline Hedging & $\begin{array}{l}\text { Participant co-constructs lexical understanding through } \\
\text { cooperative talk by managing disappointment }\end{array}$ \\
\hline
\end{tabular}

Excerpt 1: Interaction features sample analysis 
A: The word I have here shows a place, that is a name of a place in which people should have certain equipment, well people usually have plan to go to this place that is a place that most people like to experience. (Scaffolding starts)

B: Is it a place for people to gather? (Confirmation check)

A: Yes.

B: Most people like to experience. (Repetition)

A: Yes they can gather, socialize. That is a fun place people like to experience. Ok? (Comprehension check)

B: Is it cinema? (Confirmation check)

A: That is not cinema but a fun activity, I think it takes a longer time than going to the cinema this word has association with a number of equipment that we bring with ourselves.

B: When do we go there? (Clarification request)

A: Yes we can go there on weekend, $\mathrm{u}$ know we need sleeping bags since in that place you need to sleep somewhere so you need the sleeping bags, you also needs some pegs in order to fix the place you are going to stay the night there.

B: What is needed for fixing? (Request for repetition)

A: Pegs?

B: Ahan.

A: We may some necessary equipment since you are going to stay there in the night. (hedged opinion)

B: Like going camping? (Confirmation check)

A: Yes that's fine that's a place for that ...

B: Campsite? (Confirmation check)

A: Yes. (Scaffolding ends, ZPD is reached)

\section{RESULTS}

From an SCT standpoint, the investigation of interactive features reveals how languaging progresses as participants work cooperatively. Languaging mediated new knowledge about words and was helpful in activating cognitive processes of explaining and guessing the missing information that was perceived in the learners' dialogic activity. Through languaging, learners relied on a number of interaction features that assisted them to shape an understanding of the language.

Here, it will be explained how learners interact through languaging. Previously, categories of learners' interaction features were introduced (e.g., scaffolding, clarification requests, confirmation checks, comprehension checks, repetitions, requests for repetition, and hedgings). In this section the episodes will be analyzed considering the interaction features which further describe how languaging develops in interactions that target lexical items. The excerpts below demonstrate how interactive features function in LLREs in which vocabulary is addressed.

Excerpt 2: Interaction features

A: Here I have a word which is used for some kinds of evaluation. (Scaffolding starts, A takes the expert role)

B: Some kinds of evaluation? (Confirmation check)

A: Yes, evaluations which can sometime be unfair, did you get what I am saying? (Comprehension check)

B: Unfair evaluation, can you explain more? (Clarification request)

A: Well you know you may have an idea or opinion which is not based on facts.

$\mathrm{B}$ : This idea is related to what? (Clarification request)

A: It could be about anything, it could be about many different things for example about people, about happenings, you know it shows point of view. (Hedged opinion)

B: U mean ideas? (Confirmation check)

A: Yes, I guess this type of evaluation is sometimes unfair. (Hedged opinion)

B: Is it going to harm people? (Clarification request)

A: Sometimes yes because I think such evaluation may not have real value, when we have ideas feelings experiences about different things.

B: U mean biased ideas? (Confirmation check)

A: Good, it is a synonym for the word I am explaining.

B: Subjective? (Confirmation check)

A: Yes. (Scaffolding ends, ZPD is reached)

Excerpt 12: Interaction features

A: This word shows that someone is ready to do anything without worrying about the dangers. (Scaffolding starts)

B: Can you explain more? (Clarification request)

A: Yes, you know the person is not worried about danger to himself or herself because the person does not think of future.

B: Does not think of future. (Repetition)

A: I mean he or she thinks that he cannot be successful in future and that's way he thinks that this is the end of life.

B: Risk taker? (Confirmation check)

A: No, he or she does not think of success in future, have you heard the expression he is ate the end of the rope?

$\mathrm{B}$ : At the end of the rope. (Repetitions) 
A: I think some people get this feeling after having poor life. (Hedged opinion)

B: Poor life? (Confirmation check)

A: Or maybe this feeling is followed when there is no success, understand? (Comprehension check)

B: Please explain more. (Clarification request)

A: You know the person gets this feeling when everything he has done has failed.

B: Hopeless? (Confirmation check)

A: Very good but this is a word showing the same meaning.

B: Desperate? (Confirmation check)

A: Yes. (scaffolding ends, ZPD is reached)

Excerpt 3: Interaction features

A: Ok, you know this word can be used in different contexts for example I think it can be used in political contexts when ordinary people sometimes think of politics as being separated from their life ok? (Scaffolding starts + Comprehension check)

B: Please clarify. (Clarification request)

A: We have an expression in this regard, people say it's none of my business, for example some people do not believe interfering in politics is good.

B: The meaning of this word is none of my business? (Confirmation check)

A: Yes this is an adjective which shows that some matters are totally separated from other matters, it may also be used when people are doing their own jobs and people say that this is not our duty. (Hedged opinion)

B: What do people say? (Clarification request)

A: It is not our duty, many people consider politics separated from their lives, not associated.

B: Can this word be used in other situations? (Clarification request)

A: It could be about every kind of argument, matter, discussion, you say it's not associated with my life, job, issue ok? (Comprehension check)

B: Irrelevant? (Confirmation check)

A: Yes. (scaffolding ends, ZPD is reached)

Excerpt 4: Interaction features

A: Well this word explains a condition which happens when we have a loud noise overhead. (scaffolding starts)

B: Loud noise over head. Can you explain more? (Repetition + clarification request)

A: This is a kind of sound ok? (Comprehension check)

$\mathrm{B}$ : Is it a noise? (Confirmation check)

A: Yes a loud sound.

B: Is it made by animals? (Confirmation check)

A: No, This is a very loud sound.

B: By humans?

A: No by nature.

B: By nature. (Repetition)

A: I think this word is related to roar. (hedged opinion)

B: What? (Request for repetition)

A: Roar, and related to rain drops (Repetition)

B: Rain drops. (Repetition)

A: Related to words such as torrent and booming.

B: Booming sound? (Clarification request)

A: Yes.

B: People get frightened? (Confirmation check)

A: Sometimes if they are out, they are shocked right? (Comprehension check)

B: Ok

A: In cloudy weather we have it.

B: Thunder? (Confirmation check)

A: Yes. (Scaffolding ends, ZPD is reached)

To recognize features of languaging used by students, the episodes were examined to take into account the interaction features used in the LLREs. The results indicate that students use a wide range of interaction features in their collaborations. Actually, the participants utilized these strategies so as to gain regulation, mediate vocabulary meaning, and move the less proficient learners through their ZPD.

Interactive features in languaging can cause checking, dismissing, and improving formerly learned knowledge; i.e., linguistic items that learners were exposed to in their previous language learning experiences. These features help learners generate a scaffolding structure in the LLREs in which meaning discovering is made and ZPDs are reached that lead to explaining and remembering of the target word.

The use of interactive features fostered metalinguistic awareness and encouraged learners' self-regulation. Learners got involved in an investigation of the target word in which they made ideas out-loud and generated hypotheses which 
they tested and rejected based on their understanding of the interaction. Participants also decided which features are applied to infer knowledge that is indicative of how they were moving towards self-regulation as they tried to come to the linguistic answers.

\section{DiSCUSSION AND CONCLUSION}

The research question considers characteristics of languaging, namely; interaction features that facilitate lexical meaning making process. In explaining languaging characteristics SCT ideas will be used, concepts such as roles (expert and novice), regulation, ZPD, and private speech. Participants made use of these ideas to have cooperative interaction. SCT frameworks are valuable in explaining features of languaging when lexical related interaction is at its core. Through collaboration, participants took roles (expert and novice), regulated one another, and made use of private speech.

Roles. In the current research, one learner had the expert role and the other was the novice. In their LLREs learners employed a variety of interaction features as they took roles, assisted each other, and cooperated. Previous studies (as cited from Nassaji, 2006) indicate that many issues are involved in learners' use of interactive features including the nature of the word and the discussion that incorporates the word (Parry, 1993; Paribakht \& Wesche, 1999), the information given by the peer (Dubin \& Olshtain, 1993), the novices' capability to utilize cues (Haastrup, 1991), the significance of the discussed word to understanding the discourse (C. M. Brown, 1993), the extent of cognitive effort given to the task (Fraser, 1999; Joe, 1995), and the participants' presumptions about the possible word (Frantzen, 2003).

This study shows that more proficient participants were more active in using interaction features, which supports the conclusions by Fraser (1999) and Nassaji (2004). The background semantic system of the students defines the richness of the interaction features used. Clearly, this structure grows cumulatively, that is the increase in the use of inferencing strategies happens gradually.

In this study interaction features have many values. Firstly, the use of these features allows learners to be collaboratively engaged in the completion of the task without the help of the researcher. Secondly, discussion of the words with the use of interaction features in episodes can increase their mastery of the word and its various uses. By employing interaction features, learners can practice seeking information and making predictions of the word in future contexts.

Regulation. Other-regulation and object-regulation is connected to interactive features between participants. Participants use interaction features for other and object regulation. For other regulation interactive features such as scaffolding, Requests for repetition, clarification requests, confirmation checks, comprehension checks, repetitions, and hedging are used to verify information, comprehend a concept, and generate meaning. These features developed collaborations between novices and experts. Students made use of object-regulation considering lexical and contextual meaning of episodes to gain knowledge. In this study object-regulations are beneficial to learners who can deduce meaning from discussion. In this study learners made use of meaning in the interactions to have object regulation.

ZPD. Participants' assistance consisted of interaction features such as providing meaning, request for repetition, and confirmation checks. These interactions show moments of learners' collaborations that result in transformation and development and help learners get close to finding the missing information within their ZPDs. These interaction features indicate analysis of actions in learners' discussions and shape their cognition.

Participants take advantage of the interaction features they use. Instructors, taking into account features employed by students, should predict difficulties learners possibly will come across and recommend other appropriate features to be utilized together with those used by the learners already (Beena, 2010). In this research, there was no explanation provided by the instructor about LLREs, and these features were used naturally as learners developed these skills with practice and experience. Still introducing these interaction features is advantageous; participants integrate these strategies to their languaging sooner and even if learners already used these strategies this could raise their awareness.

\section{REFERENCES}

[1] Beena, P. (2010). Think-aloud protocol -- elicitation of strategy use and solution to learning problem. Language in India, 10(2), 273-281.

[2] Block, D. (2003). The social turn in Second Language Acquisition. Edinburgh: Edinburgh University Press.

[3] Braidi, S. M. (2002). Reexamining the role of recasts in native speaker/ nonnative-speaker interactions. Language Learning, 52, $1-42$.

[4] Brown, C. M. (1993). Factors affecting the acquisition of vocabulary: Frequency and saliency of words. In T. Huckin, M. Haynes, \& J. Coady (Eds.), Second language reading and vocabulary learning (pp. 263-286). Norwood, NJ: Ablex.

[5] Dubin, F. \& Olshtain, E. (1993). Predicting word meanings from contextual clues: Evidence from L1 readers. In T. Huckin, M. Haynes, \& J. Coady (Eds.), Second language reading and vocabulary learning (pp. 181-202). Norwood, NJ: Ablex.

[6] Ellis, R. (1999). Making the classroom acquisition-rich. In R. Ellis (Ed.), Learning a second language through interaction (pp. 211-229). Amsterdam: John Benjamins. Ellis et al. (2001)

[7] Ellis, R. \& Barkhuizen, G. (2005). Anaylzing Learner Language. Oxford: Oxford University Press.

[8] Firth, A. (2009). Doing not being a foreign language learner: English as a lingua franca in the work place and (some) implications for SLA. IRAL, 47(1), 127-156. 
[9] Foster, P. \& A. S. Ohta. (2005). Negotiation for meaning and peer assistance in second language classrooms. Applied Linguistics 26(3), 402-430.

[10] Fraser, B. (1999). What are discourse markers? Journal of Pragmatics, 31, 931-953.

[11] Frantzen, D. (2003). Factors affecting how second language Spanish students derive meaning from context. Modern Language Journal, 87, 168-199.

[12] Gass, S. \& Selinker, L. (1994). Second Language Acquisition: An introductory course. Mahwah, NJ: Lawrence Erlbaum Associates.

[13] Gass, S. \& Selinker, L. (2008). Second Language Acquisition: An Introductory Course (3rd Edition). New York: Routledge/Taylor Francis.

[14] Haastrup, K. (1991). Lexical inferencing procedures or talking about words. Tubingen, Germany: Gunter Narr Press.

[15] Lantolf, J. P., \& Thorne, S. L. (2006). Sociocultural theory and the genesis of second language development. Oxford, UK: Oxford University Press.

[16] Long, M. (1985). Input and second language acquisition theory' in S. Gass, and C. Madden (eds.), Input and Second Language Acquisition (pp.377-393). Rowley, Newbury House.

[17] Long, M. (1996). The role of the linguistic environment in second language acquisition. In T. Bhatia \& W. Ritchie (Eds.), Handbook of second language acquisition (pp. 413-468). San Diego, CA: Academic Press.

[18] Long, M. H., Inagaki, H. \& and Ortega, L. (1998). The role of implicit negative feedback in SLA: Models and recasts in Japanese and Spanish. Modern Language Journal 82, 357-71.

[19] Lyster, R. (1998). Recasts, repetition, and ambiguity in L2 classroom discourse. Studies in Second Language Acquisition 20, 51-81.

[20] Mackey, A., S. Gass, and K. McDonough. (2000). Do learners recognize implicit negative feedback as feedback? Studies in Second Language Acquisition 22, 471-97.

[21] Mitchell, R. \& Myles, F. (2004). Second language learning theories. Second edition. London: Hodder Arnold.

[22] Nassaji, H. (2004). The relationship between depth of vocabulary knowledge and L2 learners' lexical inferencing strategy use and success. The Canadian Modern Language Review/La Revue canadienne des langues vivantes, 62 (1), 107-135.

[23] NassajiI, H. (2006). The relationship between depth of vocabulary knowledge and 12 learners' lexical inferencing strategy use and success. The Modern Language Journal, 90(3), 387-401.

[24] Ohta, A. S. (2001). From acknowledgment to alignment: A longitudinal study of the development of expression of alignment by classroom learners of Japanese. In G. Kasper and K. Rose (Eds.), Pragmatics in language teaching (pp.103-120).Cambridge: Cambridge University Press.

[25] Paribakht, S., \& Wesche, M. (1999). Reading and "incidental" L2 vocabulary acquisition: An introspective study of lexical inferencing. Studies in Second Language Acquisition, 21, 195-224.

[26] Pica, T. (1992). The textual outcomes of native speaker-nonnative speaker negotiation: what do they reveal about second language learning in C. Kramsch, and S. McConnell-Ginet (eds): Text and Context: Cross-Disciplinary Perspectives in Language Study (pp. 198-235). Lexington, MA: D. C. Heath and Company.

[27] Pica, T. (1994). Research on negotiation: What does it reveal about second language learning conditions, processes, outcomes? Language Learning 44(3), 493-527.

[28] Skehan, P. (1996). A framework for the implementation of task-based instruction, Applied Linguistics 17, 38-62.

[29] Swain, M. (2001). Examining dialogue: Another approach to content specification and to validating inferences drawn from test scores. Language Testing, 18(3), 275-302.

[30] Tharp, R. G. \& Gallimore, R. (1991). Rousing Minds to Life: Teaching, Learning, and Schooling in Social Context. New York: Cambridge University Press

[31] Vygotsky, L. S. (1978). Mind in society: The development of higher psychological processes. Cambridge: Harvard University Press.

Ehsan Alijanian teaches linguistic and teaching courses in different universities and institutes of higher education. His research interests encompass cognitive and sociocultural linguistics, sociolinguistics, discourse analysis and pragmatics. His current research focuses on sociocultural linguistics, specifically on the construct of language related episodes during collaborative tasks.

Saeed Ketabi has published papers in different journals including Reading Psychology, Innovation in Language Learning and Teaching, Teaching English Language, Psycholinguistic Research, Translation and Interpreting Studies, Psychological Studies, and Advanced Studies in Humanities and Social Science.

Ahmad Moeinzadeh is an associate professor of ELT in the department of English Language and Linguistics in the University of Isfahan. He has supervised many dissertations across a wide range of topics, including syntax, morphology, language acquisiti on and learning. 